\title{
Constelações benjaminianas: um pensamento-intervenção na pesquisa em Psicologia
}

\author{
Benjamin constellations: a thought-intervention in Psychology research
}

Janaina Madeira Brito; Maria Carolina de Andrade Freitas; Suzana Maria Gotardo

Centro Universitário Salesiano; Universidade do Estado de Minas Gerais; Instituto Federal do Espírito Santo

\section{RESUMO:}

Este artigo apresenta, de modo singular, o entrecruzamento de pesquisas que partilharam um campo comum no município de Serra/ES. As pesquisadoras trabalham a noção de intervenção em duas direções: o movimento de implementação de comissões de saúde no trabalho da educação básica e a política de narratividade oriunda desta experiência. Uma pesquisa-narrativa afirma-se nas ferramentas do pensamento-escrita e dos conceitosarma, exercício de transmissão dessas pesquisas enquanto experiência de narração apontando para a Erfahrung benjaminiana. As noções de história aberta, do pensamento como mônada, da imagem dialética e do tempo de ruptura no contemporâneo forjam a política de escrita deste artigo. Localizar a memória de lutas menores e dos vencidos da história dão o tom analítico para a prática da escrita como processo de pesquisaintervenção. Esta é a constelação que problematiza a dimensão da subjetivação que atravessa políticas de produção de conhecimento da psicologia em sua interface com a educação.

Palavras-chave: Walter Benjamin; pesquisa-intervenção; processos de subjetivação.

\begin{abstract}
:
This article presents, in a unique way, the intersection of research that shared a common field in the municipality of Serra / ES. The researchers work on the notion of intervention in two directions: the movement to implement health commissions in the work of basic education and the narrative policy arising from this experience. A narrative research is affirmed in the devices of thought-writing and weapon-concepts, an exercise in transmitting these studies as an experience of narration pointing to Benjamin's Erfahrung. The notions of open history, of thought as a Monad, of the dialectical image and the time of rupture in the contemporary forje the writing policy of this work. Locating memory of minor struggles and the losers in history set the analytical tone for the practice of writing as a research-intervention process. This is the constellation that questions the dimension of subjectivation that runs through knowledge production policies in psychology in its interface with education.
\end{abstract}

Key-words: Walter Benjamin; research-intervention; subjectivation processes. 


\section{Introduzir ou Ursprung: início da força dispersiva}

Não é propriamente uma novidade reconhecer como a obra de Walter Benjamin (1892-1940) vem sendo explorada em diferentes campos da pesquisa em ciências humanas, incorrendo inclusive na conformação de um modismo acadêmico como já sugeriu Gagnebin (1993). Contudo, essa importante pesquisadora da obra do filósofo berlinense no Brasil inspira-nos a entender que se ater a esta questão não evidenciaria o caráter potencial de sua reflexão crítica. Trabalhar com o pensamento benjaminiano permite escapar de intenções totalizadoras para construir com seus conceitos-arma outras experimentações na pesquisa acadêmica, bem como no texto que se faz em efeito desta. Nossas problematizações sobre o contemporâneo consideram os riscos implicados em tais procedimentos de pesquisa, as que se movem a contrapelo da validação de uma corrente de pensamento dogmática, neste caso, apaziguadora do mal-estar que invadiria a operação com determinadas epistemologias (GAGNEBIN, 2009; ROLNIK, 1996).

Lidar com dialéticas insuperáveis, como nostálgico/vanguardista, teológico/materialista ou conservador/revolucionário, permite nos aproximar do pensamento desse autor, a partir da operação de reflexões notadamente desestabilizadoras. Trabalhamos então com um "filósofo perturbador" - nas palavras de Konder (1999), ou, um “filósofo demolidor", como apresentou Muricy (1993); pensador que lê a cultura em sua dimensão paradoxal; autor de uma historiografia tensionadora, que atualiza o passado ao mesmo tempo em que faz um movimento sincrônico de avaliação do presente. Como um criador de valores, Benjamin permite-nos constituir um determinado campo-interventivo em meio à fragmentação e à heterogeneidade que nos encontramos, para nisso, forjar como luta, estratégias de um pensamento-escrita necessariamente não formalista, um mote para a devolutiva de nossas pesquisas. Eis um “pensamento-selvagem”, que implica algum efeito de apreensão extraído pelo movimento do texto escrito, por vezes rápido e brusco. O leitor, neste momento, encontra-se necessariamente à espreita (MURICY, 1993) ${ }^{1}$.

O traço oligárquico-colonial no Brasil, constituinte de nossa cultura também penetrante nas políticas públicas, vem demonstrando com certa nitidez efeitos desastrosos nos territórios existenciais. Nas entranhas do cotidiano escolar, por exemplo, insistem toda sorte de conformidade violenta, racista, sectarista e classista. Fazer uso de um "pensamento-selvagem” como o de Benjamin é força e recusa radical à propensão meritocrática conservadora das barbáries brasileiras. Neste veio, a individualização dos 
processos de alcance dos direitos à educação, bem como a responsabilização pessoal pelo vivido empobrecido no campo educacional formal, mostra-se uma emboscada, tendo em vista que esse cenário forja sofrimentos de inúmeras naturezas.

Estes, por sua vez, tendem a ser culpabilizados em nossos dias - efeito que demanda análise pelas práticas em psicologia. Reconhecemos, portanto, que estamos imersos às ruínas de um projeto democrático, que se esfacela ainda mais a cada reforma que amplia as sujeições sociais. As incipientes políticas de reconhecimento e reparação deste estado de brutalização incrementam as reações contrárias e ainda mais brutais, assentando as variáveis lógicas da intolerância que se espraia no território nacional (SAFATLE, 2018).

Manter-nos perturbadas, nesse caso, constitui-se uma necessidade ética, a qual movimenta a aposta em certo modo de fazer pesquisa e de fazer presença nos terrenos de interface entre psicologia e educação. Presença que se efetiva na experiência de radicalização da relação, da espacialização da alteridade, da tática agonística pela qual se espera que as práticas construam processos de vida mais salutares. Acreditamos que as pesquisas no cotidiano educacional possam testemunhar nossa presença no mundo, no sentido freiriano: aquela "[...] que intervém, que transforma, que fala do que faz mas também do que sonha, que constata, compara, avalia, valora, que decide, que rompe" (FREIRE, 1996: 18).

Assim, o que se constrói com esta escrita introdutória é uma trilha para profissionais e pesquisadores que se dedicam à análise do vivido e dos processos de sofrimento no contemporâneo. Práticas e intervenções insurgentes ao tecnicismo e ao historicismo, que reafirmam outros modos de caminhar e lutar com tais problemáticas que se fazem nossas.

Uma pesquisa-intervenção analisa o sobretrabalho e os ativismos que deixam passar despercebidos detalhes do campo problemático, principalmente os que conteriam a potência em desarrumar o instituído na experiência ainda colonizada da cultura brasileira (CANGUILHEM, 2012; COIMBRA; NASCIMENTO, 2008). Sobre o desenho desse tipo de pesquisa, Coimbra e Nascimento (2008: 147) afirmam: “[...] a análise de implicações nos retira dos portos seguros, dos caminhos lineares e conhecidos, da paz das certezas, no jogando em alto mar, no turbilhão de dúvidas, da diversidade, e dos contornos indefinidos". Nos relatos de nossas pesquisas, ver-se-á que é inevitável sentir um certo nível de vertigem ${ }^{2}$. 
Durante o período de 2012 a 2018 atuamos no campo empírico constituído por uma pesquisa-intervenção na educação básica do município de Serra/ES, participando de um coletivo que investiga políticas de subjetividade, de saúde e de educação ${ }^{3}$.

Mesmo desenvolvendo diferentes frentes de trabalho, intentamos construir análises dos efeitos das políticas de narratividade, assentando referências históricoinstitucionais nas políticas educacionais e formativas (BRITO, 2016; FREITAS, 2018; CHAMBELA, 2018). Juntas, nossas pesquisas, fizeram-se como práticas de produção de conhecimento composicionais, configurando percursos teóricos e objetos de atenção aguçados pela emergência processual de um campo compartilhado. No presente artigo, diante do vivido - em termos da Erlebnis benjaminiana, quer dizer, do encontro factual com o campo empírico em Serra/ES, com os espaços-tempos escolares e as transversalidades institucionais que neles operam - apresentaremos cortes na singularização de uma experiência, apontando para algo da Erfahrung.

A tradução dúbia destes termos: Erlebnis e Erfahrung, que em Português costuma utilizar-se do mesmo signo "experiência”, demanda um refinamento no tratamento destas concepções, já que Benjamin as qualifica de maneira radicalmente diferente. A Erlebnis é utilizada como referência a uma vivência individual, modo de agir-sentir do sujeito privado. Já a Erfahrung funcionará aqui como um conceito-dispositivo, que orienta uma prática de narração explicitada nas modulações hermenêuticas do próprio campo empírico, nas efetivas políticas de escrita trabalhadas.

Num texto de sua juventude, datado de 1913, que leva, no original alemão justamente o nome Experiência, o filósofo ataca a noção de acúmulo de saber, tomandoa como "a máscara do adulto" que torna inválidos os saberes e as ações juvenis (BENJAMIN, 2009a).

Tornaremos útil esta pista benjaminiana para o desdobramento do presente artigo. Apresentaremos exercícios na construção da escrita que sirvam a uma política de transmissibilidade para as pesquisas-intervenção, trazendo a emergência do cronista da história como mote para o pesquisador. Efeito de uma experiência de formação coletiva, quando a produção de saúde no trabalho é tomada pela transversalidade e pelo plano instituinte (PAULON, 2005). Por meio da estratégia interventiva de implementação e formação de comissões de saúde de trabalhadores ${ }^{4}$ em escolas de uma rede municipal de educação básica, esperamos demonstrar uma processualidade na narração-escrita que valorize as ressonâncias do experimentado (CRUZ et al., 2020). 


\section{Túmulo, totalitarismos e outras alegorias do campo de pesquisa processual}

Ao pensamento pertencem tanto o movimento quanto a imobilização dos pensamentos. Onde ele se imobiliza numa constelação saturada de tensões, aparece a imagem dialética. Ela é a cesura no movimento do pensamento. Naturalmente, seu lugar não é arbitrário (BENJAMIN, 2018: 788).

Benjamin é um pensador de seu tempo. A racionalidade de sua época precisava responder aos acontecimentos nada anacrônicos que confluíram na deflagração da II Guerra Mundial. Na França, prisões de "elementos suspeitos”, estrangeiros em situações duvidosas. O nazismo instaurando um efeito-assassínio generalizado. Neste cenário de assaltos e bombardeios em todas as direções, a social-democracia alemã foi a esquerda que se colocou em pleno anacronismo interpretativo. Benjamin, de origem judaica, chegou a ser internado em dos campos de concentração nazistas - "Campo de Trabalhadores Voluntários" (Nevers) -, sendo libertado apenas pelo intermédio de alguns amigos influentes (KONDER, 1999). Na alegoria de um momento de proteção, uma momentânea paz, encontra-se, na verdade, um aviso de perigo: a queda das últimas ilusões. Digamos que esperanças estavam continuamente sendo solapadas, já que um acordo político brutal é a mensagem da destruição da experiência e da desmoralização radical. Estamos em plena autorização à tirania. A partir daí, devemos estar atentos aos efeitos do que se pode constituir massacre ${ }^{5}$.

Trazemos a partir de agora uma constelação do campo problemático em meio às ressonâncias da vida-obra de Benjamin. A obra explicita como sua filosofia compõe para desnaturalizar práticas que reiteram lógicas de saber-poder hegemônicas: processos que insistem em reificar efeitos na produção de subjetividades massificadas e docilizadas em formas inertes. Diríamos de saída que, como simulacros da estabilização dos modos de vida, do conforto da referência identitária, dos habitats já conhecidos, o que se propaga é certa efetivação do processo de exploração capitalista produzindo indivíduos, processos de vida (e de pesquisa) como clones. Assim já apresentara Rolnik (1997) ao discutir os efeitos da angústia de despersonalização, o terror ao fracasso e a insistente produção de invisibilidade e morte que continuam a marcar as políticas de existência.

Para nós, tais aspectos começam a aludir modos cada vez mais esvaziados de sentido nos mundos do trabalho no campo educacional. A pesquisa-intervenção perspectiva constituir outra paisagem, outras imagens, composições e forças; construir processos de subjetivação singulares em uma experiência, por exemplo, que radicalize o 
ensaio democrático. Exercício de atenção e crítica coproduzido com os partícipes da pesquisa. Habitar políticas públicas interpelou-nos por um pensamento social que configurasse movimentos instituintes, paisagens dialógicas, exercícios participativos. Democratizar a pesquisa e o próprio movimento do pensamento torna-se um meio de nos colocar no enfrentamento ao fantasma do totalitarismo moderno que nos ronda. Definido como um estado de exceção, não negligenciamos que este intenta a eliminação física, mas sobretudo a morte moral de cidadãos e polifonias, já encarnados como adversários políticos elimináveis (AGAMBEN, 2004).

Uma estranha anedota sobre a história de vida e de morte de Benjamin, o pensador-inclassificável, auxilia-nos no ainda premente diagnóstico desta modernidade, necessário à extração de traços marcadores da subjetivação contemporânea. Neste prisma, a vida individual é inseparável da vida social. O valor da memória individual está na restauração do eco da memória social, como nos aponta-nos Gagnebin (1993) na seguinte passagem:

\begin{abstract}
Alguns meses após a morte de Walter Benjamin, a filósofa Hannah Arendt tentou localizar seu túmulo no cemitério de Port Bou, cidade fronteiriça entre a Espanha e a França, onde ele havia se suicidado na noite de 26 para 27 de setembro de 1940. Ela encontrou o cemitério que domina o mar; do nome de Benjamin, nenhuma marca. Anos depois, entretanto, como numerosos visitantes indagavam onde Benjamin havia sido enterrado, o guarda do cemitério começou a levar os turistas a um túmulo improvisado, arranjando assim um pouco de dinheiro em troca de uma informação fictícia. (...) Essa história grotesca e macabra que G. Scholem, velho amigo de Benjamin, conta no final de seu livro de memórias, poderia servir de alegoria: na ausência de um lugar preciso onde situar a própria existência de Walter Benjamin, os que lhe sobreviveram continuam a se debater sobre um túmulo erigido para defender interesses divergentes (GAGNEBIN, 1993: 7-8).
\end{abstract}

Fazem parte do efeito perturbador as tentativas de enquadrar Benjamin em uma corrente de pensamento e até mesmo de um grupo político (no caso, o Partido Comunista), mesmo que, diferentemente, ele seja perpassado por forças menores ${ }^{6}$, sob influência do socialismo libertário; do anarcosindicalismo e do marxismo. Em certa medida, ele escapa à tentativa de "empresas científicas", pois se atenta aos perigos intrínsecos do progresso técnico no quadro da civilização burguesa moderna. $\mathrm{O}$ autor alemão sabia que o negócio capitalista se sofisticava em improvisar túmulos e gestar uma política de morte, inclusive, a partir de táticas como a de esconderijos grotescos, seja no incremento do anonimato, seja na sofisticação da contabilidade de corpos. Aqueles inumeráveis. Hoje, ainda inumeráveis (LOWY, 2013).

Mas "Os números são nomes" - é este o dizer cortante de um dos Fragmentos 
Políticos de Benjamin (BARRENTO, 2013a). No fragmento 62, que articula a Filosofia da História à política, o autor nos mostraria que qualquer número possui espaço histórico, são nomeações com contextos e paisagem. Em nossas pesquisas, quando verificamos a banalização dos processos de adoecimento na educação, reduzindo-os à generalização da vivência de desgaste e precarização, assim como constrangendo o processo de sofrimento vivenciado nos crescentes números de atestados médicos apresentados por professores e outros profissionais da educação, alude-se que, sorrateiramente, este caminho pode produzir a invisibilidade das histórias a que se referem, promovendo disjunção entre as singularizações e os acontecimentos sociais, políticos, tecnológicos e científicos que as compõem. Nessa esteira, percebemos, por exemplo, que atestados médicos não são "representações do vivido". Tampouco sua contabilidade falaria, por si, sobre uma problemática política-social-subjetiva complexa como a saúde no trabalho em educação.

A partir daí sinaliza-se que o documento que atesta e contabiliza, também encarna uma medida de governo que controla e interdita singularizações. A produção de crenças massificadas passa pelo lastro da quantificação, mas não se mostra suficiente em dizer de uma experiência mais expandida em torno dos processos de saúde e doença. Atestados são dispositivos úteis em uma maquinaria que precisa de atestados. Constituem-se, assim, como indício. Falam, assim, mais fortemente da política diagnóstica, da demarcação de uma ação clínico-assistencial, dos modos de legitimar as formas de sofrimento e do sistema de possibilidades inaugurados, inclusive, pela chance da partilha ou não do sofrimento experimentado (DUNKER, 2015).

Esses e outros processos são percebidos, assim, sob a inspiração desse olhar benjaminiano, que nos permite entrar "nos domínios do irracional" pelo perspectivismo - princípio pelo qual as veredas da pesquisa desenham o que é colocado em análise (MURICY, 1993).

$\mathrm{O}$ autor alemão faz crítica à modernidade de um modo atento a experiência coletiva dos vencidos da história (LÖWY, 2013; GAGNEBIN, 2006). Dito de outra maneira: "sua atenção se voltava, com frequência, para os aspectos que costumavam ser desprezados, ou, polidamente, ignorados, pela cultura que prevalecia, então, tanto à direita como à esquerda" (KONDER, 1999: 17). No Arquivo N, do livro das Passagens (BENJAMIN, 2009b), vamos encontrar justamente a estratégia da montagem, na qual estilo e estruturação da temporalidade textual se interpõem enquanto teoria do conhecimento. “[...] Montagem cuja edição está impregnada pela saturação de 'agoras' e 
faz explodir a continuidade da história linearmente transcrita" (DINIZ, 2009: 75). Fica evidente que se trata de uma aposta metodológica no desvio da compreensão lógicomatemática e da factibilidade absoluta do vivido. É o distanciamento daquela dimensão erlebnis da experiência que se abala para dizer que "a verdade" está em outro lugar. O túmulo é outro. O corpo do morto não se encontraria. Essa alusão compõe profundamente com a dimensão processual das pesquisas-intervenção. Nas palavras de Benjamin:

Método é caminho não direto. A representação como caminho não direto - é esse o caráter metodológico do tratado. A sua primeira característica é a renúncia ao percurso ininterrupto da intenção. O pensamento volta continuamente ao princípio, regressa com minúcia à própria coisa. Este infatigável movimento de respiração é o modo de ser específico da contemplação (BENJAMIN, 2013a: 16).

A conceitualização benjaminiana nos convida a um modo contemplativo ativo. A linguagem, nessas pesquisas, torna-se então, ação. Uma linguagem que não transmite nada senão ela mesma. Escrita com sentidos de artesania e a partir de um mosaico de imagens alusivas. As imagens na filosofia espacial benjaminiana fazem ver materialidades de pesquisa completamente inusitadas. Não basta descrições exaustivas, seja de fatos ou conteúdos. Um messianismo ${ }^{7}$ explicitando a realidade do mundo faz uso da imagem como urgência da ação histórica revolucionária. No método de escrita e na atividade da crítica em nossas pesquisas, uma estratégia de montagem alegórica apoiaria a aposta de transmissibilidade, tornando-se procedimento de comunicação de improváveis fontes, a princípio desconexas. Tudo remete à experiência enquanto tentativa de alcance da erfharung. Lembramos que, na esteira dos estóicos, a alegoria é esta linguagem outra, que separa os leitores do texto literal, permitindo que a intensidade crie aberturas e passagens ao que parece inominável, indizível ou incompreensível (GAGNEBIN, 2006).

Ao estilizar com as ideias de Marx, sem nunca ter sido propriamente um marxista - na acepção dos intelectuais da época -, esse pensador foi capaz de defender-se de incansáveis bombardeios, do desespero como afeto politizado e da vertigem como linguagem corporal, efetuando assim uma atividade de enfrentamento às piores barbáries de seu tempo. E o faz, taticamente, a partir de grandes altitudes, perturbados relevos e novos ângulos, como se observa em seus ensaios e fragmentos políticos. Para Löwy (2013: 18): “O produto dessa operação será a invenção de um novo marxismo, atravessado de estilhaços messiânicos e românticos". Para Agamben (2005) estamos diante de um método "micrológico e fragmentário". O autor continua: Benjamin 
[...] jamais assimilou completamente a concepção da mediação universal que, tanto em Hegel como em Marx, instituiu a totalidade. Sem jamais se desviar, ele se mantém fiel a seu princípio de que a mínima célula de realidade intuída contrabalança todo o resto do mundo. Para ele, interpretar materialisticamente os fenômenos significava menos explicá-los com base no todo social que relacioná-lo no seu isolamento, a tendências materiais e a lutas sociais (AGAMBEN, 2005: 139).

As lutas sociais também se localizam nos detalhes do cotidiano de uma pesquisa. Trazer à visibilidade o que faz bloqueio ao ensaio democrático; o mecanismo de alusão de onde e como estão os corpos; e também as micro revoluções, os movimentos divergentes, os gestos sutis de resistência. Tudo isso processualiza o conhecimento. Não esqueçamos que a modulação subjetiva, resultante das táticas da exploração capitalista, também exige luta reparadora da barbárie histórica brasileira. A subjetivação implica uma política e um trabalho da memória. Está no horizonte metodológico de nossas análises: qual mínima célula-fragmento-cena-lembrança tem força suficiente para contrabalançar o resto do mundo?

Benjamin esforçou-se por construir como mônada uma teoria do conhecimento e uma escritura que fossem coerentes com seu trabalho de crítica à noção de tempo e história, uma "narratividade poética do histórico", salienta Diniz (2009: 74). É por uma espécie de fagulha, fresta, brecha que nos encontraremos com a prática da narração. Um mundo infinito de veredas textuais e de significações; como arte de contar sem ter que explicar tudo e sem encerrar os acontecimentos em uma versão final; como "forças germinativas" que conservam, no tempo, o efeito de produzir aberturas a reflexões, pensamentos, espantos, novas composições. Exercitarmo-nos enquanto cronistas do cotidiano de políticas públicas de educação. Nisso, nosso campo de pesquisa estará sempre sendo (re)contado, mostrando-nos, com isso, que a história permanece aberta (BENJAMIN, 2012; GAGNEBIN, 1993).

\section{O pesquisador-cronista da história}

Um prosador chinês observou que o unicórnio, justamente pelo fato de ser anômalo, pode passar despercebido. Os olhos vêem o que estão habituados a ver; Tácito não percebeu a Crucificação, embora seu livro a registre (BORGES, 2008: 206).

Escrever é exercitar-se num jogo dialético com o real, assumir a distância do mesmo. É empenhar-se em letras oriundas do trabalho com a memória. Escrever e rememorar são jogos com o estado da palavra viva. Costurar uma experiência é trabalho inventivo, de dimensões políticas e desejantes incalculáveis a priori. É também agenciar- 
se a um saber que não pode ser antecipado ao próprio ato de narrar. O saber mobilizado pela pesquisa-intervenção-narrativa se faz neste ato, com ele e além dele. Diríamos que nesta, o inscrito, ainda que em estado de dissolução constante, produz a conjunção de duas ações de dimensões efetivamente éticas: escrever e ler. São estes movimentos distintos que se configuram numa constelação infinita, como um poetificado que sustenta passagem através de uma porta entreaberta. Semelhante à poesia, que ao escapar à linguagem pragmática e mecânica produz uma entrada sensível de composição articulada com o outro, que também a experimenta. Ou ainda, à crônica, como nos situa Benjamin (1992), que se difere da historiografia clássica à medida que o cronista é o narrador da história e quando ele a conta, não está obrigado a explicá-la.

Ao contrário do historiador tradicional, o cronista pode apostar no insondável devir do mundo. Dirá Ferreira (2017: 129): “O trabalho do cronista da história não se realiza sem uma discussão sobre a reminiscência, ou seja, sem uma dedicação ao trabalho de compor um fio narrativo que reconheça a relação entre as temporalidades históricas". Em nossa estratégia de pesquisa, o espírito do cronista liga-se ao do narrador, pois conduz o leitor aos tempos em que as pedras e o seio da terra dizem juntos os destinos das gentes. A aposta está na perspectiva de que "a magia libertadora de que o conto dispõe não põe em cena a natureza de uma forma mítica, mas é a indicação da sua cumplicidade com o homem libertado" (BENJAMIN, 1992: 49-50).

Se é pelo gesto que se gesta algo, o cronista da história pode mostrar que empenhar um modo de narrar o que se passa dos movimentos em que se está incluído, é encaminhar uma política do contar. Esta não se define pela informação que veicula, mas sim pelas marcas germinativas que emergem nas coisas que narra, tanto para aquele que viveu, como para aquele que participa do que escuta ou lê. Ainda com Ferreira (2011), a partir dos estudos benjaminianos, entendemos a narratividade como um modo de enunciação tecido e aportado na leitura política do tempo histórico. Eis aqui uma profunda ligação com o modo como fazemos as pesquisas, já que contar histórias pode se constituir como instrumento para uma análise do presente, que abra vistas à dignidade das lutas menores.

Ferreira (2011) ressalta que o trabalho de pesquisa em ciências humanas, que sustenta a narratividade como índice e escritura, deve considerar o caráter coletivo do que se enuncia, uma vez que as histórias e a palavra do outro permitem ao pesquisador um diagnóstico da atualidade em coprodução. Isto porque os rastros desse encontro evidenciam "a dissolução da centralidade da enunciação na biografia de quem fala" (FERREIRA, 2011: 130). Em suas palavras: 
Quando as questões individuais remetem-se às conexões comerciais, políticas e coletivas, muitas outras história agitam-se em seu interior, deixando de poder ser consideradas como expressão de uma vida particular auto-centrada. Em Walter Benjamin, por exemplo, tratava-se de um estudo da própria infância como uma experiência que diluía, na articulação de uma forma de escrita, a unidade do eu daquele que escrevia. Politicamente, os fragmentos transmitidos pelo narrador são como sementes que mantêm seu poder germinativo para além do tempo cronológico, dependendo dos nexos que os ouvintes consigam reconhecer em suas próprias reminiscências a partir dos perigos com que se confrontem social e politicamente (FERREIRA, 2011: 131).

Os encontros de uma pesquisa e as formas de contá-los constituem complexo processo interacional, dado pela natureza dialógica do discurso e pelo caráter interventivo das composições em curso. Isto significa para nós que o que se inscreve nas escrituras, devolutivas, testemunhos de uma pesquisa, participa de um espaço inter-relacional, de forças variadas, em que os discursos presumem diferentes vozes. O outro com o qual estabelecemos nossa conversação não é apenas um interlocutor virtual. É agenciamento dinâmico. A língua, como nos sugere Bakhtin (1997), é concreta e viva, e não se reduz a um mero objeto linguístico. Podemos, por isso, compor modos desviantes de expressão da experiência coletiva, que não se reduzam ao reinante e ao instituído, ao massificado e generalizado. Aqui localizamos a aposta em uma elaboração do passado, e uma experiência com a temporalidade que intervém de maneira distinta da obtusa linearidade, pretensiosa e hegemônica, de certa racionalidade histórica.

Os fragmentos recolhidos pelo caminho, assumindo as forças do pensamentointervenção, permitem que os debates realizados pela pesquisa não se pretendam dados puros, sólidos, fixos, imutáveis. Dados de pesquisa instituem-se e se desvanecem, como um conhecimento potencialmente perspectivo.

O delineamento de um "campo" faz-se como constelação de dados fluidos e instáveis, de modo semelhante à interpretação musical, inferida a partir da variação dos sons, sensível à composição melódica e sua execução coletiva. É nesse sentido que o fazer pesquisa-intervenção também alça dimensão de uma experiência. Ela, apontada para o diagnóstico do que nos atravessa, testemunha seu próprio nível de exame, como movente e cambiante. Embora guarde um marco interpretativo, não pretende esgotar a si mesma, explorando ao máximo seu caráter mostrativo e desviante.

Ginzburg (2001) apresenta em "Olhos de Madeira" o estranhamento como procedimento literário e como antídoto contra a banalização da realidade. Declara que há, por vezes, uma ideia absurda de que a existência humana seja previsível: "de que a guerra, 
o amor, o ódio, a arte, possam ser encarados com base em prescrições prontas; de que conhecer signifique, em vez de aprender com a realidade, sobrepor um esquema a ela" (2001: 41).

Contra isso, o autor lembra a escrita de Proust, na qual o leitor é posto diante de gestos e palavras incompreensíveis, sem dispor de uma explicação de ordem causal, mantendo-se um certo mistério. Há nesta, ainda, uma ambiguidade na voz que narra, com a qual, a partir de uma série de fragmentos contraditórios, compõe-se um quebra-cabeça ou uma adivinha. Neste ponto, situamos agora um diálogo com a experiência-adivinha, que relança a escritura e a produção do saber numa direção infinita. Aposta em suas conexões, distancia-se do tratamento exaustivo de qualquer fator recolhido em percurso. Para pesquisadores-cronistas implicaria: "Compreender menos, ser ingênuos, espantarse, são reações que podem nos levar a enxergar mais, a apreender algo mais profundo" (GINZBURG, 2001: 29). O efeito do estranhamento constituiria em resguardar certa leitura da história, que como afirmou Proust, seria preciso para pintá-la como Elstir pintava o mar: ao revés.

Tendo isso em vista e seguindo as pistas fornecidas por Hacking (2009), escrever e pesquisar são modos de recolher ínfimos detalhes de situações historicamente existentes para traçar um plano de análise que não procura limitar-se por concepções especulativas, mas confronta a realidade, por considerar que as formas investidas por qualquer analítica descrevem temporalidades e enunciados possíveis e situados.

Fica evidente que nossas pesquisas não buscam verdades ou falsidades das proposições encontradas, e sim assumem que tais proposições são sempre formações discursivas geradas e produzidas sob certas condições de possibilidade. Visto que a narração no sentido benjaminiano tem efeitos inconclusos, "narrar é abrigar o inacabamento do tempo histórico", como bem apontou Ferreira (2011: 130).

Para o pesquisador-cronista da história, o campo é produzido em interesse e controvérsias que constituem questões políticas e enfatizam a reinvenção de sentidos, a criação de histórias, de vínculos, de relações de força favoráveis à sustentação da produção de diferença e engendramento de multiplicidades (STENGERS, 1990).

Narrar uma experiência de trabalho, uma pesquisa e uma escritura trata-se de fiar detalhes. Fiar por meio da linguagem, a vida e a labuta, num exercício de testemunho assumir certa posição de escrevente e de contador - dos movimentos realizados em luta, sempre. Porque só podemos falar em movimento se, em meio às batalhas para empenhar o vivo mutante, nos situamos em meio a essas lutas que traduzem embates constantes. 
Nosso conhecimento é necessariamente datado e provisório, adota sempre uma posição de referência. Ali infere. Cria uma nova espacialidade, pois referir-se a algo produz corpos reais. Não seria isto, a própria tarefa do pensamento-intervenção? Criar, ao mesmo tempo que as formas, também suas dissoluções? Aquilo que não cessa de engendrar-se e desfazer-se. A intervenção seria criar existências-processos e, com elas, enfrentar o totalitarismo das identidades inertes, através delas, arremessar linhas inéditas para a subjetivação nos processos de vida e trabalho na escola, por exemplo (PROUST, 1988).

\section{A forma-força da escrita: deitar em imagem um possível}

Uma pesquisa de inspiração institucionalista pressupõe a emancipação do pensamento. Este percorre um modo de dizer, contar, narrar experiências que atingem nossos corpos e ultrapassam as "tentativas de certeza" sem, contanto, perderem suas apostas políticas de insistir na vida, nas forças e na produção de novas formas de vivertrabalhar-pesquisar.

Corpos-de-conhecimento, corpos reais, são - em alguma medida - corpos em uso, desajeitados nos movimentos, disparatados em seus interesses, abestalhados em seus fazeres. São ainda tentativas de se enfrentar o corpo do túmulo, frio e indiferente. Em se tratando da ciência da subjetividade (CANGUILHEM, 2012), isso não cria nenhum descrédito ao movimento da pesquisa ou às proposições que se fazem a partir dela. Pelo contrário, ajudam-nos a reafirmar que estamos menos interessadas em rígidos trabalhos burocráticos e muito mais em produzir outra corporeidade em torno do registro e da publicização dos efeitos das pesquisas. Compor corpus de possibilidades. "Nunca pode haver história acabada”, afirma Hacking (2009: 111). Que seja isto: o que afirmamos são histórias intrincadas. Experiências recalcitrantes.

Para o dialético, o que importa é ter o vento da história universal [Weltgeschichte] em suas velas. Pensar significa para ele: içar velas. O que é decisivo é como elas são posicionadas. As palavras são suas velas. O modo como são dispostas transforma-se em conceitos. [...] Ser dialético significa ter o vento da história nas velas. As velas são os conceitos. Porém, não basta dispor das velas. O decisivo é a arte de posicioná-las. (BENJAMIN, 2018: 784).

Constelar é um modo de produzir subjetividades reafirmando outros corpos, iluminações textuais, choques críticos, narratividades. Barrento (2013b) indica-nos que os procedimentos dos surrealistas tentavam fazer convergir imagens cruzadas e inesperadas para a emergência do universo profundo das ligações imperceptíveis. Tal 
como no sonho, esta é uma tática de crítica ao subjetivismo. A ousadia é podermos aprender algo aí, já que os surrealistas quiseram escrever de forma automática: esperavam fazer surgir o "real da memória" pelas interpolações.

Lembramos aqui que as imagens criadas por Baudelaire de sua Paris sobre-real, bem como as de Benjamin (2015), são resultado de uma percepção anamnésica que recupera toda sorte de fragmentos do passado para construir uma visão do espaço e uma experiência com outra dimensão de tempo (BARRENTO, 2013b). Assim também se intensifica o trabalho de memória do pesquisador. Pensamento-intervenção desajeitado. Parece estar em certa posição recuada frente aos acontecimentos. Não pode - no momento dos acontecimentos - dizer do que será capaz de registrar. Este funcionamento num tempo a posteriori faz-nos encarar, mais uma vez, a precariedade do vivo. O "só depois" é também o tempo da lembrança do fulgor e do instante revivido, que cria uma lacuna fecunda e perigosa. Espaço de um entretempo em que o interesse em escrever sobre dado tema, manifestadamente - como suporta a etimologia da palavra "interessar" - cria o "estar entre" (STENGERS, 1990: 100).

Sob esse prisma, a querela da verdade-falsidade precisa ser recolocada em termos outros. Trata-se de afirmar que, para produzir diferença e apostar num modo de ver perspectivo, é preciso dispor-se a vencer a "lenda de ouro da ciência" positivista hegemônica: a de que a verdade pode se dar a um indivíduo por iluminação, fazendo outros reconhecerem tal brilhantismo e o seguirem. Mais uma vez, deparamo-nos com os imperativos dos movimentos de massa (STENGERS, 1990: 100). Mas, para nós, o ouro que reluz é outro: aquele que fornece a centelha da vela, da lembrança, do detalhe. Centelha, brilho, que permanece entre nós, ainda quando não há "verdade" alguma. A fagulha que, desconsertando a memória-baú, faz superficializar cenas, imagens, palavras, túmulos, atestados médicos... Os avistamos somente por vislumbre. Insurgência. Consistência. Nesta perspectiva, não somos interioridades consubstanciadas.

Pesquisa-intervenção e as subjetivações são efeitos de poder. Alunos, professores, pesquisadores, psicólogos são falanges. Multidões humanas e não-humanas. Somos o que pudemos constituir-nos politicamente e em concerto - de imagens, sensibilidades, corpos. Somos o desvio das identidades e previsibilidades. Somos a própria provisoriedade dos diagnósticos indigentes, mudos, sem paisagem. Como inflexiona Benjamin: "o que são desvios para os outros, são para mim os dados que determinam a minha rota. Construo meus cálculos sobre os diferenciais de tempo - que, para outros, perturbam "grandes linhas da pesquisa" (2009b: 498). 
Barrento (2013b) lembra-nos que o método benjaminiano de escrever a contrapelo utiliza-se de três estratégias de memória: a) o ensaio sociológico, que sustenta a mediação entre a base social e econômica e a superestrutura da criação poética; b) a escrita das memórias, que não realiza apenas um "inventário dos achados", mas assinala o momento exato em que o passado cruza ou se atualiza no presente e; c) a montagem surrealista, memória involuntária que automatiza os lugares de passagem, transmutando-os em vestígios férteis de apresentação de uma experiência.

A escrita de nossos textos torna-se, assim, uma escrita viva, atendendo a imperativos próprios, imanente à operação da própria memória. A forma costumeira de apresentação do argumento e da intencionalidade pode então se perturbar. O vivido de cada uma de nós se esvanece. É assim que o pesquisador, com sua verdade soberana e totalitária, também se esfumaça. "Não é o sujeito que dispõe da sua memória, é a memória (involuntária, recordação ou rememoração, presentificação anamnésica) que dispõe dele, sob as mais diversas formas e nas mais diversas linguagens" (BARRENTO, 2013b: 107). Testemunhamos esse efeito-transmissibilidade ao final dessa perlaboração. O fim do artigo é o próprio começo daquilo que ele reverbera sobre nossas políticas de vida, sobre o que nos acossa no contemporâneo, algo que nos interpela agora.

Todo presente é determinado por aquelas imagens que lhe são sincrônicas: cada agora é o agora de uma determinada cognoscibilidade. Nele, a verdade está carregada de tempo até o ponto de explodir. (Esta explosão, e nada mais, é a morte da intentio, que coincide com o nascimento do tempo histórico autêntico, o tempo da verdade.) Não é que o passado lança luz sobre o presente ou que o presente lança sua luz sobre o passado; mas a imagem é aquilo em que o ocorrido encontra o agora num lampejo, formando uma constelação. Em outras palavras: a imagem é a dialética na imobilidade. Pois, enquanto a relação do presente com o passado é puramente temporal, a do ocorrido com o agora é dialética - não de natureza temporal, mas imagética. (BENJAMIN, 2018: 768).

Agamben (2009), em “O que é contemporâneo?” faz uma pergunta: quem é, e do que somos contemporâneos? Com tal provocação, remete-nos à questão e à compreensão do tempo sob a perspectiva de uma kairologia. Ao relembrar Barthes, define o contemporâneo como o intempestivo. Suscita-nos retornar a Nietzsche, em "O nascimento da tragédia", no ponto em que este configura sua crítica à febre da história. Desse modo, para que nos remetamos ao contemporâneo, precisamos assumir certa desconexão em relação ao presente, já que o contemporâneo, para o autor, não coincide perfeitamente com a atualidade.

Nesses termos, o efeito de análise da pesquisa-intervenção assume que a relação 
com o tempo guarda uma dissociação e um anacronismo singular. Isso produziria uma proximidade do contemporâneo com a figura do poeta: aquele que devia pagar sua contemporaneidade com a vida, aquele que enquanto contemporâneo, constitui-se como fratura, impedindo o tempo de compor-se precisamente. Como os versos do poeta que afirmam as vértebras quebradas do século. Trata-se de um gesto impossível: para quem tem o dorso quebrado, é impossível virar-se para trás para contemplar as próprias pegadas (AGAMBEN, 2009).

Quando, em nossas produções acadêmicas, enunciamos intentar "produzir saúde no trabalho em educação" - essa sentença que pode ser lida como mero jargão de pesquisas da área -, não falamos de outra coisa que não "mudar o mundo", e, como entendemos com Agamben (2016), mudar o tempo. Certamente, não mudaremos nossa época e seu modo hegemônico de se produzir trabalho-vida; tampouco a forma como ela será contada às gerações vindouras. A única mudança que podemos empreender é a de tomar "nosso tempo" - reavermo-nos com ele. Encontrá-lo e recriá-lo por entre as ruínas do ordenamento que expropria a experiência com o trabalho. Recriá-lo em palavra, encontrando sua dimensão mágica: não falamos sobre o mundo; produzimo-lo ao falar (BENJAMIN, 2012: 117-122). Mudar o mundo, o tempo e, assim também, o modo de falar - falar junto, em comunidade: eis a convocação.

Uma cena da pesquisa-intervenção com as comissões de saúde de trabalhadores da educação pode explicitar, por fim, nuances dessa aposta. Trata-se de uma apresentação realizada em um reconhecido congresso local, no qual, em meio a falas de especialistas recrutados Brasil à fora, as trabalhadoras que se lançaram à tessitura das primeiras comissões em seu município apresentaram os resultados de tal empreitada, após um intrincado processo de planejamento coletivo, perpassado pelo zelo e cuidado com a escolha do quê e de como a experiência seria contada. Na apresentação, entre outras coisas, é exposta uma série de ações pensadas e realizadas em suas escolas; são trazidas indagações, mudanças em modos de organizar o trabalho e mesmo de postura frente a certas contingências sobre as quais as participantes exerciam menos poder de gerência. Apresentam um plano de ações. Mas, como observam, a saúde não está no plano de trabalho, no projeto, nas ações a serem empreendidas: a saúde já se presentifica ali, no próprio processo de elaboração das estratégias, na produção de um outro modo de se tomar o trabalho, de vivê-lo, de pensá-lo junto, na dinâmica mesma de composição que por efeito resultou num produto plano de ação ou em alterações práticas no cotidiano profissional. É um pequeno e gigantesco deslocamento, cuja expressão mais incisiva 
encontramos na fala de uma dessas trabalhadoras: "O que a gente pode dizer que mudou na escola? Talvez nada visível em grande escala. Mas mudou a forma como a gente tem lidado com os problemas. Estamos mais fortalecidas".

\section{(In)conclusões e transmissibilidade: a história inacabada e os rastros em derivas}

Contemporâneo é aquele que mantém o olhar fixo no seu tempo, ainda que de vértebras quebradas e dissociado do próprio tempo; nele, entrevê o escuro. Habitar um mundo, um tempo, uma experiência no sentido da Erfahrung, pressupõe lidar com certa escuridão. Escuridão que não é cegueira, mas um tatear por fendas. Escuridão como modo particular de visão. Certas luzes podem cegar. A escuridão não é uma experiência anônima, é algo que interpela, como "aquele que recebe em pleno rosto o facho de trevas que provém do seu tempo" (AGAMBEN, 2009: 64). Se o dorso do tempo está fraturado, jamais somos alcançados pelo presente.

Essa é a urgência-coragem que emerge da presença nas políticas públicas: no escuro do presente, perceber certa faísca de luz para nós dirigida, convidando-nos, interpelando por práticas que, ao mesmo tempo, estão situadas na infinita distância de nós! Intempestividade atordoante. Paradoxo. Instituir, produzir ações entre um "ainda não" e um “não mais", guardando um limiar inapreensível, um ágio (AGAMBEN, 1993), espaço livre, intervalar, que nos remete ao movimento pendente e inexorável do devir histórico. Em última instância, o contemporâneo não é apenas aquele que capta a resoluta luz por meio do escuro de seu presente, mas aquele que interpola o tempo com outros tempos, fazendo saltar modos de ler e citar a história de forma singular.

Assim, o que pôde nascer do encontro de nossas pesquisas - como este artigo -, foi, mais uma vez, a ideia de uma nova narração, outra forma de perspectivar o vivido, uma retomada. Narrativa que se faz com pouco; tessitura sobre histórias ordinárias, relegadas, esquecidas. Um mergulho na vida, para aí ver algo produzindo heterogênese.

Trazemos, para transtornar os ditos dados de pesquisa, Walter Benjamin, pesquisador alegórico, aquele que carrega uma concepção que, entendemos, traduz o processo de pensamento-escrita na ordem das intensidades, das agonísticas, do impensado, do estranhamento. Munidas de seus conceitos-arma, continuamos a abrir frestas nos edifícios das certezas, convocando outro ethos na condição de problematizar os processos de saúde/adoecimento/morte no contemporâneo, vislumbrando possíveis ágios onde algo com a força e a inapreensão de uma experiência-Erfahrung possa se 
constituir como estratégia de luta e resistência. Desnaturalizamos os cortejos. Fabricamos analisadores. Mobilizamos alguma disposição insurgente face à expropriação e alienação que acede a própria vida ao caráter de mercadoria sem equivalência, na época do completo domínio desta forma em todos os aspectos da vida social - forma que se alça, falaciosamente, numa "submissa e insensata promessa de felicidade" (AGAMBEN, 1993: 42).

Na contramão de um positivismo que ainda parece vencer no âmbito das políticas de produção de conhecimento, resistimos em afirmar a experiência vivida como tecido que cria e transforma o mundo, como consistência a sustentar nosso próprio empreendimento. Nas devastações cotidianas, ali onde parece tudo sucumbir, um novo plano de possível se efetiva - aquém e além dos projetos e estabilidades. Lançadas aos abalos sísmicos das políticas governamentais, intentamos transmitir uma condição de desassossego. Colocamos em jogo, assim, um esforço em direção à construção de formas de expressão que deem passagem à precariedade que nos acomete, uma colagem com os cacos que nos restam. Como extrair das ruínas possíveis outros? O que emerge nessa condição de fazer-se sobre as ruínas? Essa é a tensão, como força de atração, que congrega, numa disposição um tanto quanto instável, fragmentos diversos. Aí reside nosso método de produção de conhecimento, não apenas na forma-produto do texto acadêmico, mas em outras de nossas inserções no mundo. É essa nossa estratégia de luta.

\section{Referências}

AGAMBEN, Giorgio. A comunidade que vem. Portugal: Editorial Presença, 1993.

AGAMBEN, Giorgio. Estado de exceção. 2. ed. São Paulo: Boitempo, 2004.

AGAMBEN, Giorgio. Infância e História: destruição da experiência e origem da história. Belo Horizonte: UFMG, 2005.

AGAMBEN, Giorgio. O que é o contemporâneo? Chapecó: Argos, 2009.

AGAMBEN, Giorgio. O tempo que resta: um comentário à Carta aos Romanos. Belo Horizonte: Autêntica, 2016.

BAKHTIN, Mikhail. Problemas da poética de Dostoiévski (1929). 2. ed. Rio de Janeiro: Forense Universitária, 1997.

BARRENTO, João. Comentários. In: BENJAMIN, Walter. $O$ anjo da história. Organização e tradução de João Barrento. 2. ed. Belo Horizonte: Autêntica, 2013a. p. $165-261$.

BARRENTO. Limiares sobre Walter Benjamin. Florianópolis: UFSC, $2013 \mathrm{~b}$.

BENJAMIN, Walter. Sobre arte, técnica, linguagem e política. Lisboa: Relógio D’Água, 1992. 
BENJAMIN, Walter. Reflexões sobre a criança, o brinquedo e a educação. 2. ed. São Paulo: Duas Cidades; Ed. 34, 2009a.

BENJAMIN, Walter. Passagens. São Paulo: UFMG; Imprensa Oficial do Estado de São Paulo, 2009b.

BENJAMIN, Walter. Magia e técnica, arte e política: ensaios sobre literatura e história da cultura. 8. ed. São Paulo: Brasiliense, 2012.

BENJAMIN, Walter. Origem do drama trágico alemão. 2. ed. Belo Horizonte: Autêntica, 2013a.

BENJAMIN, Walter. Rua de mão única / Infância berlinense: 1900. Belo Horizonte: Autêntica, 2013b.

BENJAMIN, Walter. Baudelaire e a modernidade. Belo Horizonte: Autêntica, 2015.

BENJAMIN, Walter. Passagens. Belo Horizonte: UFMG, 2018.

BRITO, Janaína Madeira. Loucas docências benjaminianas: política da narratividade e produção de saúde. 2016. Tese (Doutorado em Educação) - Programa de PósGraduação em Educação, Universidade Federal do Espírito Santo, Vitória - ES.

BORGES, Jorge Luis. Antologia pessoal. Tradução de Davi Arrigucci Jr., Heloisa Jahn e Josely Vianna Baptista. São Paulo: Companhia das Letras, 2008.

CANGUILHEM, Georges. Estudos de história e de filosofia das ciências: concernente aos vivos e à vida. Rio de Janeiro: Forense, 2012.

CHAMBELA, Suzana Maria Gotardo. Narrar em nosso tempo: experiência e saúde no trabalho em educação. 2018. Tese (Doutorado em Educação) - Programa de PósGraduação em Educação, Universidade Federal do Espírito Santo, Vitória - ES.

COIMBRA, Cecília Maria Bouças; NASCIMENTO, Maria Lívia. Análise de implicações: desafiando nossas práticas de saber/poder. In: GEISLER, Adriana Ribeiro Rice; ABRAHÃO, Ana Lúcia; COIMBRA, Cecília Maria Bouças (Orgs.). Subjetividades, violência e direitos humanos: produzindo novos dispositivos em saúde. Niterói: UFF, 2008, p. 143-153.

CLOT, Yves. Trabalho e poder de agir. Belo Horizonte: Fabrefactum, 2010.

CRUZ, Cristiane Bremenkamp; BRITO, Hervacy; FREITAS, Maria Carolina de Andrade; ROCON, Pablo Cardoso; GOTARDO, Suzana Maria. Tessituras do pesquisar-intervir com comissões de saúde no trabalho em educação. Curitiba: CRV, 2020.

DELEUZE, Gilles; GUATTARI, Félix. Mil platôs - capitalismo e esquizofrenia. Rio de Janeiro, Ed. 34, 1995. 2. v.

DINIZ, Davidson de Oliveira. Walter Benjamin e as Passagens: uma narratividade poética do histórico. Cadernos Benjaminianos, [S.1.], n. 1, p. 74-93, dez. 2009.

DUNKER, Christian Ingo Lenz. Mal-estar, sofrimento e sintoma: uma psicopatologia do Brasil entre muros. São Paulo: Boitempo, 2015.

FERREIRA, Marcelo Santana. Walter Benjamin e a questão das narratividades. Mnemosine, Rio de Janeiro, v. 7, n. 2, p. 121-133, 2011.

FREIRE, Paulo. Pedagogia da Autonomia: saberes necessários à prática educativa. São Paulo: Paz e Terra, 1996. 
FREITAS, Maria Carolina de Andrade. Nos limiares do Fora: experiência e narratividade em políticas de saúde e educação. 2018. Tese (Doutorado em Educação) Programa de Pós-Graduação em Educação, Universidade Federal do Espírito Santo, Vitória - ES.

GAGNEBIN, Jeanne Marie. Walter Benjamin: Os cacos da história. 2. ed. São Paulo: Brasiliense, 1993.

GAGNEBIN, Jeanne Marie. Lembrar, escrever, esquecer. São Paulo: Ed. 34, 2006.

GAGNEBIN, Jeanne Marie. História e Narração em Walter Benjamin. São Paulo: Perspectiva, 2009.

GINZBURG, Carlo. Olhos de Madeira: nove reflexões sobre a distância. São Paulo: Companhia das Letras, 2001.

HACKING, Ian. Ontologia Histórica. Rio Grande do Sul: Unisinos, 2009.

KONDER, Leandro. Walter Benjamin: o marxismo da melancolia. 3. ed. Rio de Janeiro, 1999.

LÖWY, Michael. Walter Benjamin: crítico da civilização. São Paulo: Boitempo, 2013.

MURICY, Kátia. Benjamin e Nietszche. Síntese Nova Fase. Belo Horizonte, v. 20, n. 63, p. $663-677,1993$.

PAULON, Simoni Mainieri. A Análise de implicação como ferramenta na pesquisaintervenção. Psicologia \& Sociedade [on line], v. 17, n. 3, p. 18-25, set/dez 2005.

PROUST, Françoise. La ligne de résistance. In: GILLES, Deleuze. Imannence et vie. Rue Descartes/20. Collège International Filosophie, Paris: PUF, mai. 1988. p. 43.

ROSSI, André; PASSOS, Eduardo. Análise Institucional: Revisão conceitual e nuances da pesquisa-intervenção. Revista EPOS, Rio de Janeiro, v. 5, n 1, p. 156-181, jan/jun 2014.

ROLNIK, Suely. Toxicômanos de identidade: subjetividade em tempo de globalização. Cultura e subjetividade: Saberes Nômades. In: LINS, Daniel (Org.). Campinas: Papirus, 1997. p. 19-24.

ROLNIK, Suely. Despedir-se do Absoluto. Cadernos de Subjetividade, São Paulo, num. esp., p. 245-256, jun. 1996.

SAFATLE, Wladimir. Só mais um esforço. São Paulo: Três Estrelas, 2018.

STENGERS. Isabelle. Quem tem medo da ciência? Ciência e poderes. São Paulo: Siciliano, 1990. 


\title{
Suzana Maria Gotardo Chambela Instituto Federal do Espírito Santo (Santa Teresa/ES) \\ E-mail: sugotardo@yahoo.com.br
}

\begin{abstract}
${ }^{1}$ Os estudos clínico-institucionais, na ciência das subjetividades, encontram outras possibilidades de transmissão quando elaboram sobre a natureza da filosofia entrelaçada às práticas em psicologia. Tal exercício permite colocar em análise os "instrumentalismos" da psicologia - na pesquisa e na prática profissional, aqui sem cisão, pois tratamos sobretudo do processo que institui determinado plano éticopolítico para tais modos de produção de saber-fazer (CANGUILHEM, 2012).
\end{abstract}

${ }^{2}$ Embora posicionado no campo institucionalista, o presente artigo não aprofunda conceitos-ferramentas que localizam a pesquisa-intervenção no debate com a pesquisa-ação enquanto referências de pesquisas qualitativas. Para este intento sugerimos a sistematização recente feita por Rossi e Passos (2014).

${ }^{3}$ Referência ao Programa de Formação e Investigação em Saúde e Trabalho (PFIST), vinculado ao Núcleo de Estudos e Pesquisas em Subjetividade e Política (NEPESP) - Departamento de Psicologia/ Universidade Federal do Espírito Santo -, coordenado pela Profa. Dra. Maria Elizabeth Barros de Barros.

${ }^{4}$ Apesar de não nos propormos, no presente artigo, a tratar de modo mais direto as nuances do trabalho com as referidas comissões - as quais temos denominado por Cosates -, podemos brevemente defini-lo como aposta na organização destas como espaço-tempo de atenção e intervenção relativas à saúde no local de trabalho. Visa fomentar, a partir da análise situada das condições de trabalho, estratégias de enfrentamento coletivo a modos organizativos que produzem sofrimento, deslocando-o de uma relação individualizada e produzindo referenciais compartilhados que ampliem a capacidade de criação e o poder de agir no trabalho (CLOT, 2010). Tal estratégia é abordada com detalhes em Cruz et al. (2020).

${ }^{5}$ Digamos que o efeito-Füheur seja inestimável. Um momento histórico determinado põe em análise o lugar do século XX, a racionalidade da guerra de eliminação, as multidões banidas da história. A extrema pobreza da experiência da Humanidade. A reprodução da imoralidade, da fome e da inflação. Passamos a encarar, sem ilusões, a ameaça premente dos microfascismos como realidade cotidiana. Uma palavra de ordem purista e absoluta, intolerante e violenta, está na política de nossos dias, assim como a violência crua está para a condução das massas (BRITO, 2016).

6 Tomamos a referência de Deleuze e Guattari (1995) ao usarmos a expressão "menor", que aqui não expressa minorias em termos de quantidades numéricas ou adjetivação de pouco valor. Trata-se, em outro sentido, do que desvia de um certo padrão, do não homogêneo, do que coloca em choque um modo de vida hegemônico.

7 Termos como "messiânico", "Messias", “salvação" e "reino de Deus" são frequentes no conjunto da obra benjaminiana e remetem a um uso muito peculiar, na filosofia do autor, de elementos da teologia judaica, fundidos a noções marxistas. Tal prática suscitou leituras diferentes e divergentes de seus comentadores. Dentre esses, seguimos o entendimento de Gagnebin (1993), segundo a qual os temas místicos na filosofia da história benjaminiana não significam que o autor tenha pretendido transpor uma doutrina religiosa da salvação para termos marxizantes. A articulação entre o que Benjamin chama de "teologia" e "materialismo histórico" são vistos como antídoto ao positivismo e conformismo presentes na historiografia burguesa, e também latentes na teoria pretensamente científica do progresso defendida pela social-democracia. 